\title{
Gerontology and scientometrics ("Citogerontology")
}

\author{
Alexander N. Khokhlov \\ Evolutionary Cytogerontology Sector, School of Biology, Lomonosov Moscow State University, Moscow, Russian Federation \\ khokhlov@mail.bio.msu.ru
}

\begin{abstract}
Based on his experience in working as a member of Editorial Boards of some scientific journals and Elsevier/Scopus Expert Content Selection and Advisory Committee (Russian Federation), as well as Associate Editor-in-Chief of Moscow University Biological Sciences Bulletin, the author analyzes current situation with publications in the field of experimental and theoretical gerontology. Special attention is paid to scientometric indices and ranking of the papers, relevant journals, and authors. Some predatory journals in the field are considered too. Various approaches to improving scientometric indices of authors involved in gerontological research are proposed.
\end{abstract}

Keywords - gerontology, aging, publications, scientific journals, indices, metrics, ranking

In recent years, scientometric indicators (number of citations, impact factor, Hirsch index, SJR index, etc.) of their work efficiency have become increasingly important for scientists of various specialties. Unfortunately, it is precisely such indicators, and not the essence of the research conducted by the authors, that are now often decisive for reviewers from various foundations providing research grants. And gerontology/biology of aging in this regard are no exception. In order to get a big enough grant to study the mechanisms of aging or to develop model systems for the search for geroprotectors, it is now not enough for specialists in the field of biology of aging to submit an application to the science foundation with a description of their advanced ideas or developed research methods. In the first place, reviewers of applications pay attention to the "quality" of works already published by applicants, as well as to the relevant ratings of the authors. And by "quality" and "ratings" they mean the scientometric indicators just mentioned above (of both researchers and the journals they used to publish their results). There is a vicious circle: in order to get high-quality scientific results, you need money, and you can get it only by publishing a significant number of "cool" articles [1].

The paradox is that in many cases the journals from Q1 (25\% of journals with the highest scientometric indicators; the publications in them provide scientists with the high ratings necessary for receiving grants, as well as for re-certification or competition for prestigious posts) are not necessarily really serious about reviewing and editing manuscripts submitted to the editorial office. Moreover, they may even be the so-called "predatory journals," the appearance of which is associated with an increasingly widespread recent distribution of articles, publication of which is fully paid by the authors $[2,3]$.

A few years ago, I was already considering the situation with one small foreign publishing house specializing in gerontological journals mainly [1]. It exists for a little over 10 years and currently publishes 4 scientific journals. The impact factors of these publications reach 5-6, i.e. they can easily be classified as "highly ranked" (Q1). All of them operate within the framework of an open access model paid by the authors. The cost of publishing an article (APC - article processing charge) varies from 3 to 4 thousand US dollars. Moreover, the number of published articles is huge. For example, in the most popular journal of the publisher in 2016 about 1,500(!) articles were published, distributed among 52(!) issues. In addition, publication time is from two weeks(!), which practically excludes the possibility of a normal reviewing of manuscripts. It should be said that this journal was mentioned by the famous fighter for the purity of scientific publications, Jeffrey Beall [2, 3], on his website as a very likely "predator," but this did not prevent the journal from being indexed in international systems of global citation.

It should be borne in mind that journal ranking can be done in quite different ways. In particular, impact factor (Web of Science) and CiteScore (SCOPUS) indices are very similar; both are based on the number of citations in a given year of articles from a given journal published in the previous two (Web of Science) or three (SCOPUS) years. Therefore, the Q1-Q4 quartile distribution in these systems is quite similar. However, in the very popular SCImago Journal Rank system, based on SCOPUS data, journals are ranked according to the SJR index; this is the same citation index of the journal, but already normalized to the rating of serials in which articles are cited. If the rating of citing editions is very high, then SJR may exceed CiteScore, if it is low enough, then SJR will be lower than CiteScore - in some cases at times lower. In many scientific institutions, it is the rating based on the SJR indicator that is used in the certification of teachers and researchers.

It should be emphasized that in each area and category of knowledge there are ranks and quartiles that may not be connected in any way with these indicators in other fields of science. Say, in the subject category "Gerontology," even SJR 0.9 allows the journal to get into Q1, but in the subject category "Aging," SJR 1.7 is already needed for this. The highest ranked gerontological journal Ageing Research Reviews has SJR of 4.125, while its CiteScore has now exceeded 11. However, it is very far from the "coolest" oncological journal $\mathrm{Ca}$-A Cancer Journal for Clinicians with SJR 72.576 and CiteScore around 180.

In conclusion, I would like to note that my many years of experience as a member of the editorial board of the journal Advances in Gerontology, as well as a member of the Elsevier/Scopus Expert Content Selection and Advisory Committee (Russian Federation) and Associate Editor-in-Chief of Moscow University Biological Sciences Bulletin [4], which publishes, by the way, a significant number of articles on the biology of aging, has allowed me to assume that a highly ranked scientific journal is difficult to quickly create [5], if you do not ignore the formal requirements of international systems of global citation, implying a rigorous blind peer review, correct preparation of the manuscript, illustrations and bibliographies, as well as a serious attitude of the authors to the statistical processing of the data obtained. However, in the presence of significant financial injections, this process can be accelerated many times, but, as far as I know, the vast majority of gerontological journals that are free of charge for authors, sadly, cannot boast of this kind of financial support. 


\section{ACKNOWLEDGMENT}

Supported in terms of the state assignment of Lomonosov Moscow State University, part 2 (basic research, no. AAAAA16-116021660098-8).

\section{REFERENCES}

[1] Khokhlov A.N., Klebanov A.A., Morgunova G.V. (2017) How very bad articles are published in very good scientific journals. In: World-Class Scientific Publication - 2017: Best Practices in Preparation and Promotion of Publications: Proc. 6th Int. Sci. \& Pract. Conf., April 1821, 2017. Ekaterinburg: Ural University Press, $150-156$
[2] Beall J. (2012) Predatory publishers are corrupting open access. Nature. 489(7415): 179 .

[3] Beall J. (2013) Predatory publishing is just one of the consequences of gold open access. Learn. Publ. 26(2): 79-84.

[4] Kirpichnikov M.P., Morgunova G.V., Khokhlov A.N. (2020) Our journal -2020: what and how we publish. Moscow Univ. Biol. Sci. Bull. 75(1): 1-6.

[5] Khokhlov A.N. (2019) The worse, the better or how to quickly create a high-ranking scientific journal. In: World-Class Scientific Publication 2019: Strategy and Tactics of Management and Development: Proc. 8th Int. Sci. \& Pract. Conf., Moscow, April 23-26, 2019. Ekaterinburg: Ural University Press, 118-126. 